\title{
Influence of animals obtained using embryo transfer on the genetic evaluation of growth in Simmental beef cattle with random regression models
}

\author{
R.R. Mota ${ }^{1}$, P.S. Lopes ${ }^{1}$, L.F.A. Marques ${ }^{2}$, L.P. Silva ${ }^{1}$, \\ M. Conceição Pessoa ${ }^{1}$, R. Almeida Torres ${ }^{1}$ and M.D.V. Resende ${ }^{3,4}$ \\ ${ }^{1}$ Departamento de Zootecnia, \\ Universidade Federal de Viçosa/INCT Ciência Animal, Viçosa, MG, Brasil \\ ${ }^{2}$ Departamento de Zootecnia, \\ Centro de Ciências Agrárias da Universidade Federal do Espírito Santo, \\ Alegre, ES, Brasil \\ ${ }^{3}$ Embrapa Florestas, Colombo, PR, Brasil \\ ${ }^{4}$ Departamento de Engenharia Florestal, \\ Universidade Federal de Viçosa, Viçosa, MG, Brasil \\ Corresponding author: R.R. Mota \\ E-mail: rreismota@hotmail.com
}

Genet. Mol. Res. 12 (4): 5889-5904 (2013)

Received March 13, 2013

Accepted September 20, 2013

Published November 22, 2013

DOI http://dx.doi.org/10.4238/2013.November.22.17

\begin{abstract}
Weight records of Simmental beef cattle were used in a genetic evaluation of growth with and without embryo transfer (ET). A random regression model in which ET individuals were excluded (RRM1) contained 29,510 records from 10,659 animals, while another model that did not exclude these animals (RRM2) contained 62,895 records from 23,160 animals. The fixed and random regressions were represented by continuous functions, and a model with an order of three for the fixed curve and random effects was used to consider the homogeneity of residual variance. In general, the (co)variance
\end{abstract}


components were similar in both models, except the maternal permanent environment and residual components. The direct heritability in RRM1 and RRM2 showed the same behavior with oscillations along the growth curve and were slightly higher in RRM1. Generally, the estimated correlations were the same and smaller as the ages distanced themselves. The inclusion of animals from ET in genetic evaluations can be done using random regression models; the inclusion of these animals would provide potential accuracy gains and greater genetic gains per unit time because of the reduction in the generation interval from the use of this reproductive technique.

Key words: Body weight; (Co)variance components; Heritability; Maternal effects

\section{INTRODUCTION}

In recent decades, the use of the embryo transfer (ET) technique in livestock provided enormous scientific progress, especially in the bovine species, as one of the reproduction biotechnologies applied (De Bem et al., 1993). This technique, combined with the selection of the best animals, can accelerate the genetic changes in the herds (Bilhassi et al., 2010).

In general, animal breeding involves the exchange or import of genetic material from other locations, countries, or continents. This exchange involves high costs of transportation and big risk in the transmission of diseases; however, these factors can be reduced or eliminated by the transportation of fresh, chilled, or frozen embryos (Dobrinsky, 2001).

ET combined with genetic evaluation offers a number of advantages for livestock selection with consequent repercussions on animal production. This fact enables the selection of dams and sires for insemination, increasing the number of offspring of genetically superior animals, reducing the generation interval, and increasing the speed of improvement (Andrade et al., 2002) and accuracy of estimates of (co)variance components and genetic parameters.

In the study of Bilhassi et al. (2010) with Simmental beef cattle using multi-trait models for weights at 100 and 120 days, higher values of direct heritability were obtained from models that included animals from the ET technique. They concluded that the inclusion of these animals in the process of genetic evaluation allows larger genetic gains in breeding programs. Results of the production of Simmental beef cattle have been large. These animals, because they have optimal performance, have resulted in farmers requesting more research about the ET technique (Demczuk et al., 1998).

Random regression models (RRM) have been used as an alternative to model longitudinal traits such as growth in beef cattle (Meyer, 1998, 2000). The application of these models allows parameters to be estimated and breeding values to be predicted for any desired age even for ages in which the animal has not been recorded - and allows the efficient use of all available information on each animal because all measures of the animal and its relatives are used for genetic evaluation with a potential increase in accuracy of estimates (Meyer, 2004). Furthermore, the use of RRM also allows changes in mean and variance of the trait over time to be considered, as well as the point of highest heritability and consequently higher genetic gain per generation to be estimated. 
Combining the technique of ET with the use of RRM seems to be an option that should be considered in genetic evaluation of animals to promote improvements in animal performance. Because of the lack of studies in the literature that include animals from the ET technique using RRM and the real possibility of progress in genetic evaluations, this study was designed to evaluate the effect of including animals from the ET technique in genetic evaluation using RRM.

\section{MATERIAL AND METHODS}

The database analyzed in this study refers to records of weights of Simmental beef cattle from 485 farms and provided by the Brazilian Association of Simmental and Simbrasil Cattle Farmers (Associação Brasileira de Criadores das Raças Simental e Simbrasil, ABCRSS) located in the municipality of Cachoeiro do Itapemirim, Espírito Santo, Brazil. Records of weight were used from the 60th to the 819th day of age from animals that were born between 1974 and 2006.

Two data files were prepared for the analysis using RRM. In the first file (RRM1), animals produced by the ET technique were excluded, whereas in the second file (RRM2), these individuals were included. The method proposed by Van Vleck (1990) was used in this analysis. This method includes the genealogy of the biological mother for estimation of the additive maternal genetic effect and the foster dams with no known genealogy and no relationship with animals present in the solution vector, thus allowing assessment of the additive direct genetic and additive maternal genetic effect, as well as estimation of the maternal permanent environmental effect. Calves of cows whose ages at birth were less than 700 and greater than 2340 days were excluded from the analysis. The contemporary group that was defined by animals of the same sex, year, season $(1=$ January to March, $2=$ April to June, $3=$ July to September, and $4=$ October to December), and the herd of animal birth were considered to be fixed effects, and the classes of the ages of dam at calving in days (class 1: 700 to 1109; class 2: 1110 to 1519; class 3: 1520 to 1919, and class 4: 1920 to 2340) were considered to be covariates with linear and quadratic effects.

In the data files for the RRM1 and RRM2, the contemporary groups had at least three animals, and weight records outside the intervals given by the mean of the contemporary group plus or minus three standard deviations were excluded. After the restrictions, RRM1 was composed of 29,510 records of 10,659 animals, which were calves of 1289 sires and 7332 cows, and RRM2 was composed of 62,895 records of 23,160 animals, which were calves of 1558 sires and 9699 cows. The numerator relationship matrix that was used in the analysis contained 41,904 animals.

Tables 1 and 2 present the descriptive statistics of the files RRM1 and RRM2, respectively. The structures of files RRM1 and RRM2 in relation to the number of records per animal are demonstrated in Table 3. The number of records and mean body weight for each age of the files RRM1 and RRM2 are presented in Figures 1 and 2, respectively.

Table 1. Descriptive statistics of the file RRM1 along the growth curve.
\begin{tabular}{rccccrc}
\hline Age (days) & N & Average $(\mathrm{kg})$ & SD $(\mathrm{kg})$ & CV $(\%)$ & Min $(\mathrm{kg})$ & Max $(\mathrm{kg})$ \\
\hline $60-149$ & 6236 & 129.73 & 29.89 & 23.04 & 63.57 & 218.54 \\
$150-299$ & 7938 & 220.20 & 49.45 & 22.45 & 106.33 & 352.85 \\
$300-419$ & 6070 & 331.93 & 77.03 & 23.20 & 166.80 & 550.49 \\
$420-499$ & 3666 & 385.17 & 89.39 & 23.21 & 183.96 & 641.73 \\
$500-619$ & 3468 & 438.03 & 100.26 & 22.89 & 210.50 & 758.35 \\
$620-811$ & 2132 & 530.44 & 125.09 & 23.58 & 250.93 & 955.15 \\
\hline
\end{tabular}

$\mathrm{N}=$ number of observations; $\mathrm{SD}=$ standard deviation; $\mathrm{CV}=$ coefficient of variation; $\mathrm{Min}=$ minimum value; Max $=$ maximum value. 
Table 2. Descriptive statistics of the file RRM2 along the growth curve.

\begin{tabular}{|c|c|c|c|c|c|c|}
\hline Age (days) & $\mathrm{N}$ & Average (kg) & $\mathrm{SD}(\mathrm{kg})$ & CV (\%) & $\operatorname{Min}(\mathrm{kg})$ & $\operatorname{Max}(\mathrm{kg})$ \\
\hline $60-149$ & 13,102 & 137.77 & 28.10 & 20.40 & 107.19 & 172.12 \\
\hline $150-299$ & 16,585 & 223.70 & 46.82 & 20.93 & 106.21 & 353.50 \\
\hline $300-419$ & 13,090 & 334.74 & 72.23 & 21.58 & 166.80 & 550.49 \\
\hline $420-499$ & 7,930 & 387.29 & 83.88 & 21.66 & 183.86 & 641.73 \\
\hline $500-619$ & 7,551 & 443.49 & 95.28 & 21.48 & 209.69 & 758.35 \\
\hline $620-811$ & 4,637 & 534.94 & 117.56 & 21.98 & 249.50 & 955.15 \\
\hline
\end{tabular}

$\mathrm{N}=$ number of observations; $\mathrm{SD}=$ standard deviation; $\mathrm{CV}=$ coefficient of variation; $\mathrm{Min}=$ minimum value; Max $=$ maximum value.

Table 3. Structure of files RRM1 and RRM2 in relation to the number of records per animal.

\begin{tabular}{lccrr}
\hline Records & \multicolumn{2}{c}{ RRM1 } & \multicolumn{2}{c}{ RRM2 } \\
\cline { 2 - 3 } & No. of animals & $\%$ & No. of animals \\
\hline Total & 10,659 & 100.0 & 23,160 & 6,473 \\
Animals with 1 record & 2,915 & 27.35 & 5,433 & 27.95 \\
Animals with 2 records & 2,401 & 22.53 & 4,352 & 23.46 \\
Animals with 3 records & 1,938 & 18.18 & 3,243 & 18.79 \\
Animals with 4 records & 1,624 & 15.23 & 2,426 & 14.00 \\
Animals with 5 records & 1,203 & 5.42 & 1,233 & 5.48 \\
Animals with 6 records & 578 & &
\end{tabular}

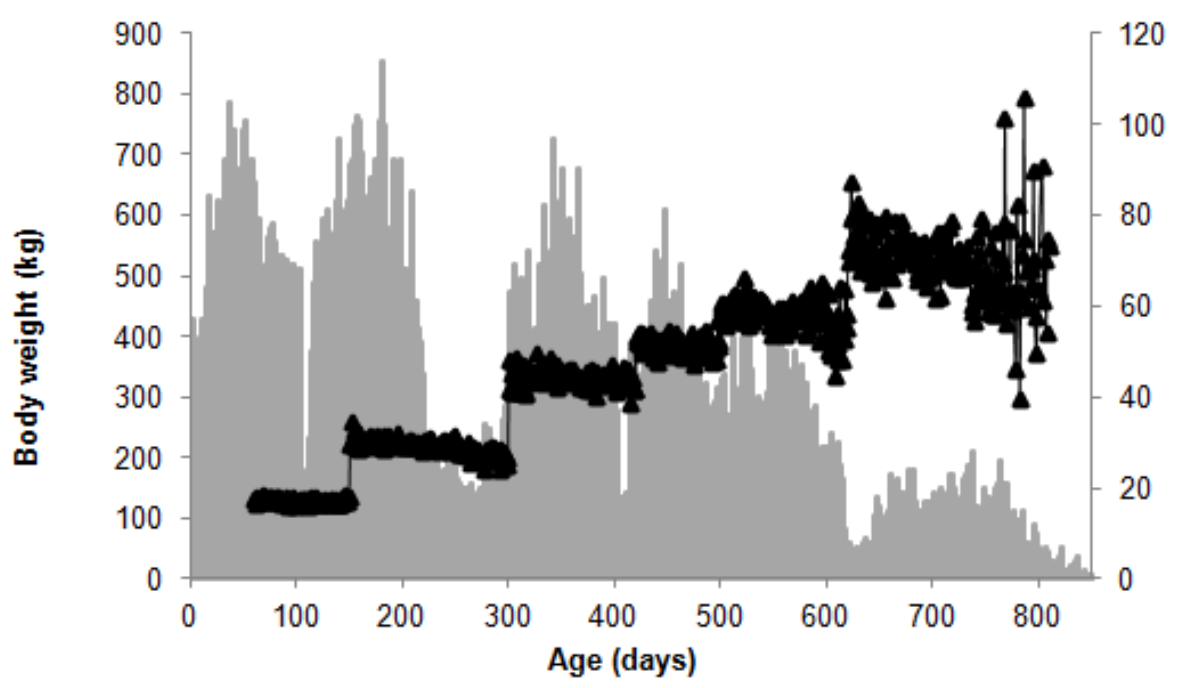

Figure 1. Number of records (gray bars) and mean body weight (black triangles) for the ages in the file RRM1.

The organization and the consistency analysis of the data files were performed using the SAS software (2004) and the estimation of (co)variance components and genetic parameters were accomplished by the method of restricted maximum likelihood (REML), which was developed by Patterson and Thompson (1971), and obtained using the program WOMBAT, which was developed by Meyer (2007). 


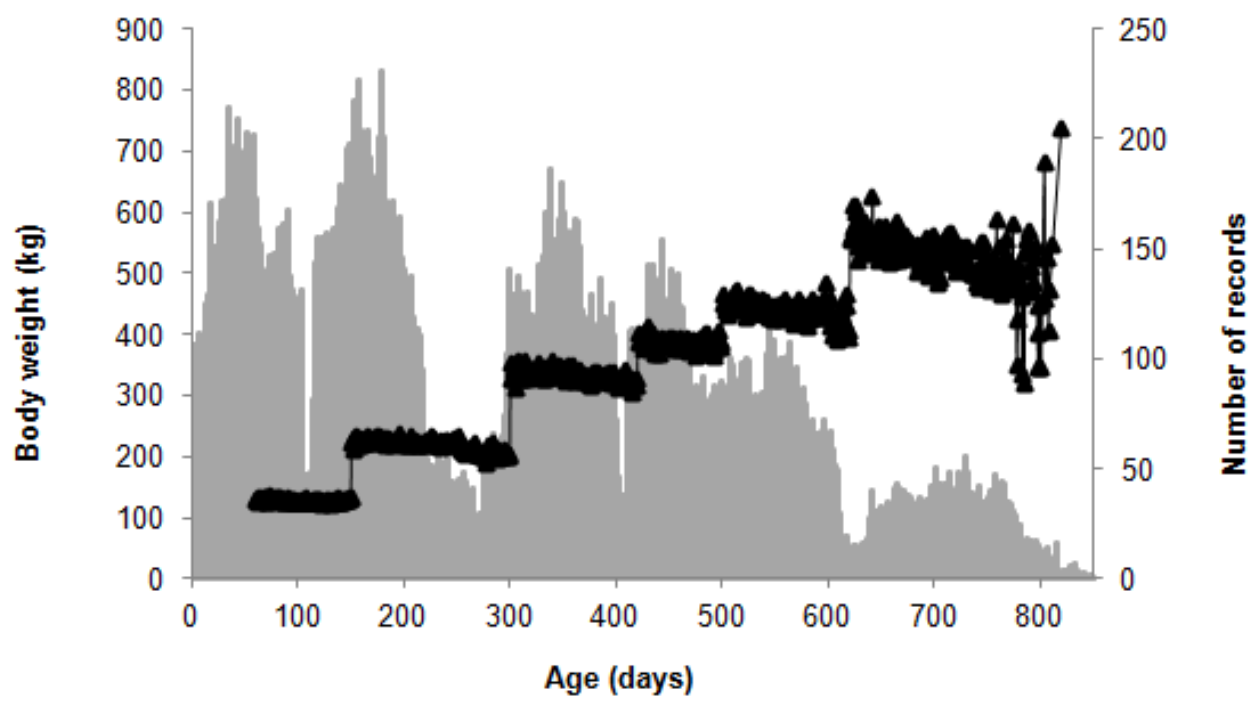

Figure 2. Number of records (gray bars) and mean body weight (black triangles) for the ages in the file RRM2.

\section{Random regression model}

The fixed and random regressions were represented by continuous functions, and the RRM of order 3 was chosen for the fixed regression curve and the random effects, 3 for direct additive genetic, 3 for maternal additive genetic, 3 for maternal permanent environmental, and 3 for direct permanent environmental.

The RRM was described as follows:

$\mathrm{y}_{\mathrm{ij}}=\mathrm{Fij}+\sum_{\mathrm{m}=0}^{\mathrm{k}_{\mathrm{p}}-1} \beta_{\mathrm{m}} \phi_{m}\left(a_{i j}^{*}\right)+\sum_{\mathrm{m}=0}^{k_{\mathrm{d}}-1} \mathrm{~d}_{\mathrm{im}} \phi_{m}\left(a_{i j}^{*}\right)+\sum_{\mathrm{m}=0}^{\mathrm{k}_{\mathrm{m}}-1} \mathrm{~m}_{\mathrm{im}} \phi_{m}\left(a_{i j}^{*}\right)+\sum_{\mathrm{m}=0}^{k_{\mathrm{mp}}-1} m p_{\mathrm{im}} \phi_{m}\left(a_{i j}^{*}\right)+\sum_{\mathrm{m}=0}^{k_{\mathrm{p}}-1} \mathrm{p}_{\mathrm{im}} \phi_{m}\left(a_{i j}^{*}\right)_{\mathrm{m}}+e_{\mathrm{ij}}$ (Equation 1)

where $y_{i j}=$ weight on $\mathrm{j}^{\text {th }}$ day of the $\mathrm{i}^{\text {th }}$ animal, $F_{i j}=$ group of fixed effects constituted by the contemporary group (sex, herd, year, and season of animal birth) and for the covariate class of age of dam at calving, considering linear and quadratic effects; $\beta_{m}=m^{\text {th }}$ fixed regression coefficient of the mean curve of population growth; $d_{\mathrm{im}}, \mathrm{m}_{\mathrm{im}}, m p_{\mathrm{im}}$, and $\mathrm{p}_{\mathrm{im}}=$ random regression coefficients relating to direct additive genetic, maternal additive genetic, maternal permanent environmental, and direct permanent environmental effects, respectively, for the $i^{\text {th }}$ animal; $k_{d}, k_{m}, k_{m p}$, and $\mathrm{k}_{\mathrm{p}}=$ orders of covariance functions used to describe the direct additive genetic, maternal additive genetic, maternal permanent environmental, and direct permanent environmental effects, respectively; $a_{i j}^{*}=\mathrm{j}$ age of the $\mathrm{i}$ animal; $\phi_{m}\left(a_{i j}^{*}\right)=$ Legendre polynomials evaluated for $a_{i j}^{*}$ for the fixed regression and direct additive genetic random, maternal additive genetic, maternal permanent environmental, and direct permanent environmental effects considering the orders of the covariance functions $\mathrm{k}_{\mathrm{d}}, \mathrm{k}_{\mathrm{m}}, \mathrm{k}_{\mathrm{mp}}$, and $\mathrm{k}_{\mathrm{p}}$, respectively; and $e_{\mathrm{ij}}=$ residual effect. 
Alternatively, in matrix notation, the model with their respective assumptions can be described as:

$$
\mathrm{y}=\mathrm{X} \beta+\Phi_{1} \mathrm{~d}+\Phi_{2} \mathrm{~m}+\Phi_{3} \mathrm{mp}+\Phi_{4} \mathrm{p}+\mathrm{e} \quad \text { (Equation 2) }
$$

As the vector $y$ is composed sequentially by age within the individual, it is possible to get the following structure of means and variances:

$$
E\left[\begin{array}{c}
y \\
d \\
m \\
m p \\
p \\
e
\end{array}\right]=\left[\begin{array}{c}
X \beta \\
0 \\
0 \\
0 \\
0 \\
0
\end{array}\right], V\left[\begin{array}{c}
d \\
m \\
m p \\
p \\
e
\end{array}\right]=\left[\begin{array}{ccccc}
\mathrm{A} \otimes k_{d} & 0 & 0 & 0 & 0 \\
0 & \mathrm{~A} \otimes k_{m} & 0 & 0 & 0 \\
0 & 0 & I_{N m} \otimes k_{m p} & 0 & 0 \\
0 & 0 & 0 & I_{N d} \otimes k_{p} & 0 \\
0 & 0 & 0 & 0 & \mathrm{R}
\end{array}\right]
$$

where $y=$ vector of observations; $\beta=$ vector of fixed effects that contains the coefficients $\beta_{m}$ of fixed regression; $d=$ vector of random regression of direct additive genetic coefficients; $m=$ vector of random regression of maternal additive genetic coefficients; $m p=$ vector of random regression of maternal permanent environmental coefficients; $p=$ vector of random regression of direct permanent environmental coefficients; $e=$ residual vector; $X, \Phi_{\mathrm{d}}, \Phi_{\mathrm{m}}, \Phi_{\mathrm{mp}}$, and $\Phi_{\mathrm{p}}=$ incidence matrices for the polynomial coefficients of the fixed effects, direct additive genetic, maternal additive genetic, maternal permanent environmental, and direct permanent environmental, respectively; $K_{d}, K_{m}, K_{m p}$, and $K_{p}=$ matrices of (co)variances among the direct additive genetic random regression coefficients, maternal additive genetic, maternal permanent environmental, and direct permanent environmental, respectively; $A=$ numerator relationship matrix among individuals; $I_{N d}=$ identity matrix of dimension $d$ (number of animals with record); $I_{N m}=$ identity matrix of dimension $m$ (number of dams with calves with record); $R=$ diagonal matrix of residual variances; and $\otimes=$ direct product operator.

The covariance between additive direct genetic and additive maternal genetic effects was assumed to be equal to zero.

\section{RESULTS AND DISCUSSION}

The direct genetic variance $\left(\sigma_{\mathrm{d}}^{2}\right)$ was similar in both models (RRM1 and RRM2), with slightly higher values in RRM1 and presented an increase along the growth trajectory (Figure 3 ). These results corroborate those found by Albuquerque and Meyer (2001) and Baldi et al. (2010), who observed a behavior of increasing along the growth curve in their studies with Nellore and Canchim beef cattle, respectively.

The lowest proportional number of dams per animal in RRM2 may have caused a lower genetic variance among animals observed in RRM2. However, the same behavior of the curve was observed for both RRM1 and RRM2, which confirms the feasibility of the animals' inclusion from the ET in the genetic evaluations of the Simmental breed. 

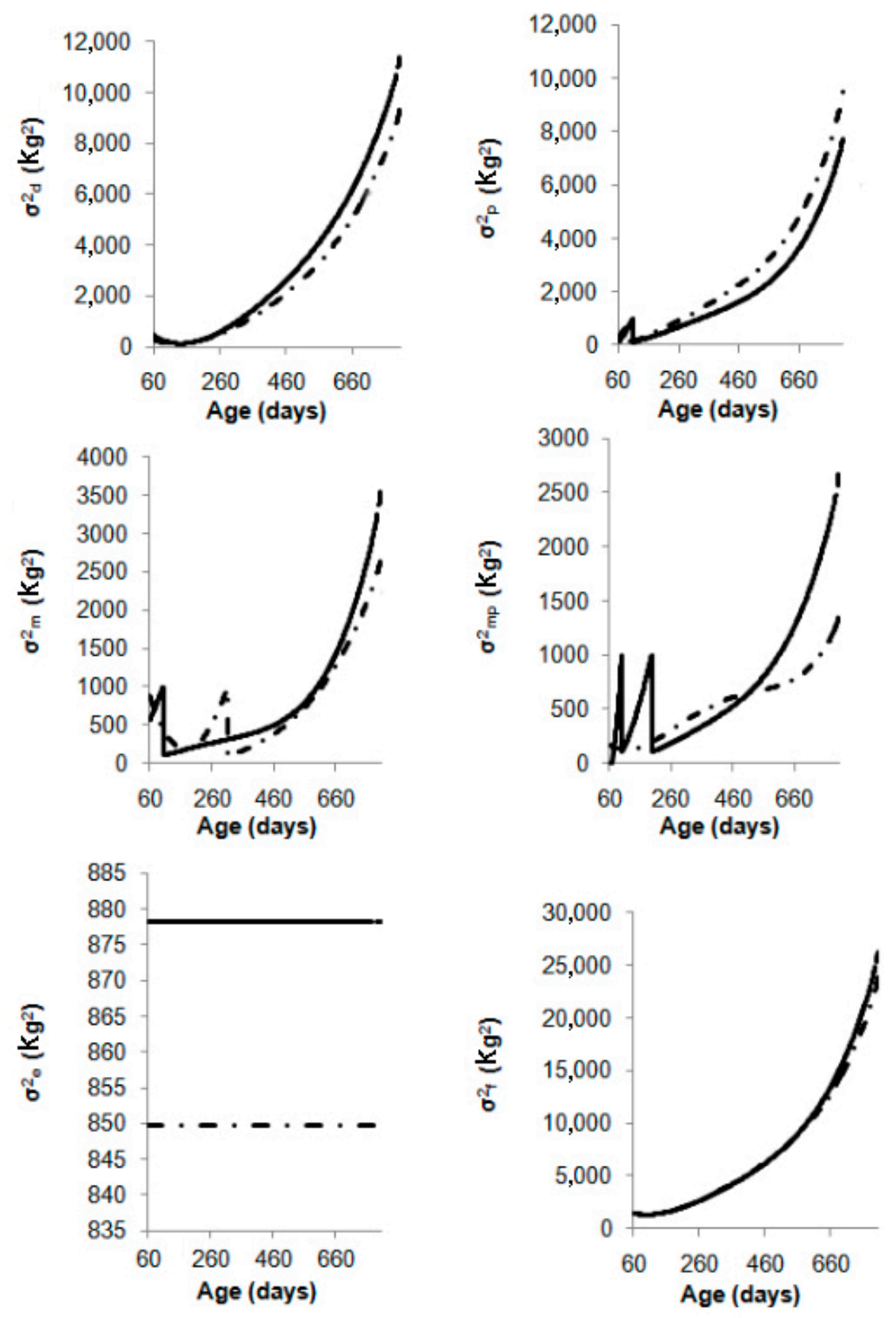

-RRM1 - - RRM2

Figure 3. Direct additive genetic $\left(\sigma^{2} \mathrm{~d}\right)$, direct permanent environmental $\left(\sigma^{2} \mathrm{p}\right)$, maternal additive genetic $\left(\sigma^{2} \mathrm{~m}\right)$, maternal permanent environmental $\left(\sigma^{2} \mathrm{mp}\right)$, residual $\left(\sigma^{2} \mathrm{e}\right)$, and phenotypic $\left(\sigma^{2} \mathrm{f}\right)$ variances estimated for the files RRM1 (full lines) and RRM2 (broken lines) for body weight. 
The estimates of variance components of direct permanent environmental $\left(\sigma_{p}^{2}\right)$ were similar throughout the growth curve, with RRM2 showing slightly superior values of this component. The behavior of RRM1 and RRM2 was increased from 60 days, but both had a decrease to 100 days old before returning to present a crescent behavior (Figure 3). Boligon et al. (2010) and Menezes (2010), in their studies with beef cattle in Nellore and Tabapuã breeds, respectively, found similar results for the direct permanent environmental variance.

The estimates of the maternal genetic variance component $\left(\sigma_{\mathrm{m}}^{2}\right)$ had generally the same behavior in both models (RRM1 and RRM2) and presented a decrease of the component in a determined interval of the crescent growth trajectory; however, these decreases happened in different intervals, close to 60 days in RRM1 and close to 260 days in RRM2. The results that were observed in RRM2 are equivalent to those found by Menezes (2010) and Sousa Júnior et al. (2010), who noted an increase of this component up to 240 days old, with a decrease after this age and a new increase from 480 days old.

According to Menezes (2010), this behavior of increasing to around 240 days is expected because this is the period in which animals suffer major influences of their dams. Thus, the observed decrease in RRM1 close to 60 days was not expected and can be probably explained by the difficulty of making accurate estimates at the beginning and end of the growth curve with the polynomial function.

The results observed for the maternal permanent environmental component $\left(\sigma_{\mathrm{mp}}^{2}\right)$ for the two models diverged at the beginning and showed similar behavior from 240 days of the growth trajectory of the animals. While $\sigma_{m p}^{2}$ presented a crescent behavior over the entire curve in RRM2, it showed an oscillation of $\sigma_{m p}^{2}$ at the beginning and an abrupt increase at 480 days old in RRM1, which was not consistent with the biological reality (Figure 3).

An inadequate fit in these intervals may have been caused by problems that were found by RRM using Legendre polynomials in the estimation of (co)variance components in the extremities of the growth trajectory. Furthermore, the low number of available records at the end of the curve can also be the reason for the abrupt growth that was observed. Dias et al. (2006) reported results that were similar to those observed in RRM2, with continuous growth from birth to 550 days old. In RRM1, Menezes (2010) also observed an abrupt increase from 480 days old; however, at the beginning of the growth curve, the behavior of RRM1 was divergent and RRM2 was similar to our results.

The estimate of residual variance $\left(\sigma_{\mathrm{e}}^{2}\right)$ in RRM1 was of superior magnitude in relation to the estimate of RRM2. This may indicate that the inclusion of animals from ET results in fewer errors and a potential gain in accuracy.

The behavior of the phenotypic variance $\left(\sigma_{\mathrm{f}}^{2}\right)$ in both models was similar and crescentshaped along the trajectory, corroborating the results found in Tabapuã beef cattle (Dias et al., 2006; Sousa Júnior et al., 2010; Menezes, 2010), Nellore beef cattle (Boligon et al., 2010) and Canchim beef cattle (Baldi et al., 2010).

Estimates of direct genetic heritability $\left(\mathrm{h}_{\mathrm{d}}{ }_{\mathrm{d}}\right)$ were, in general, similar in both models, and the mean magnitude was slightly higher in RRM1 than in RRM2. These heritabilities decreased from 60 to nearly 200 days, when an increase was observed until about 600 days old, where a new decline ensued (Figure 4). These results agree with $0.071,0.115,0.148,0.162$, $0.156,0.120$, and 0.073 for the intervals $63-113,114-164,165-215,216-266,267-317,318$ 368, and 369-420 days, respectively, as presented by Krejcová et al. (2007), who studied the Simmental cattle using Legendre polynomials of third order. Like this study, they obtained the same behavior along the growth curve of animals. 

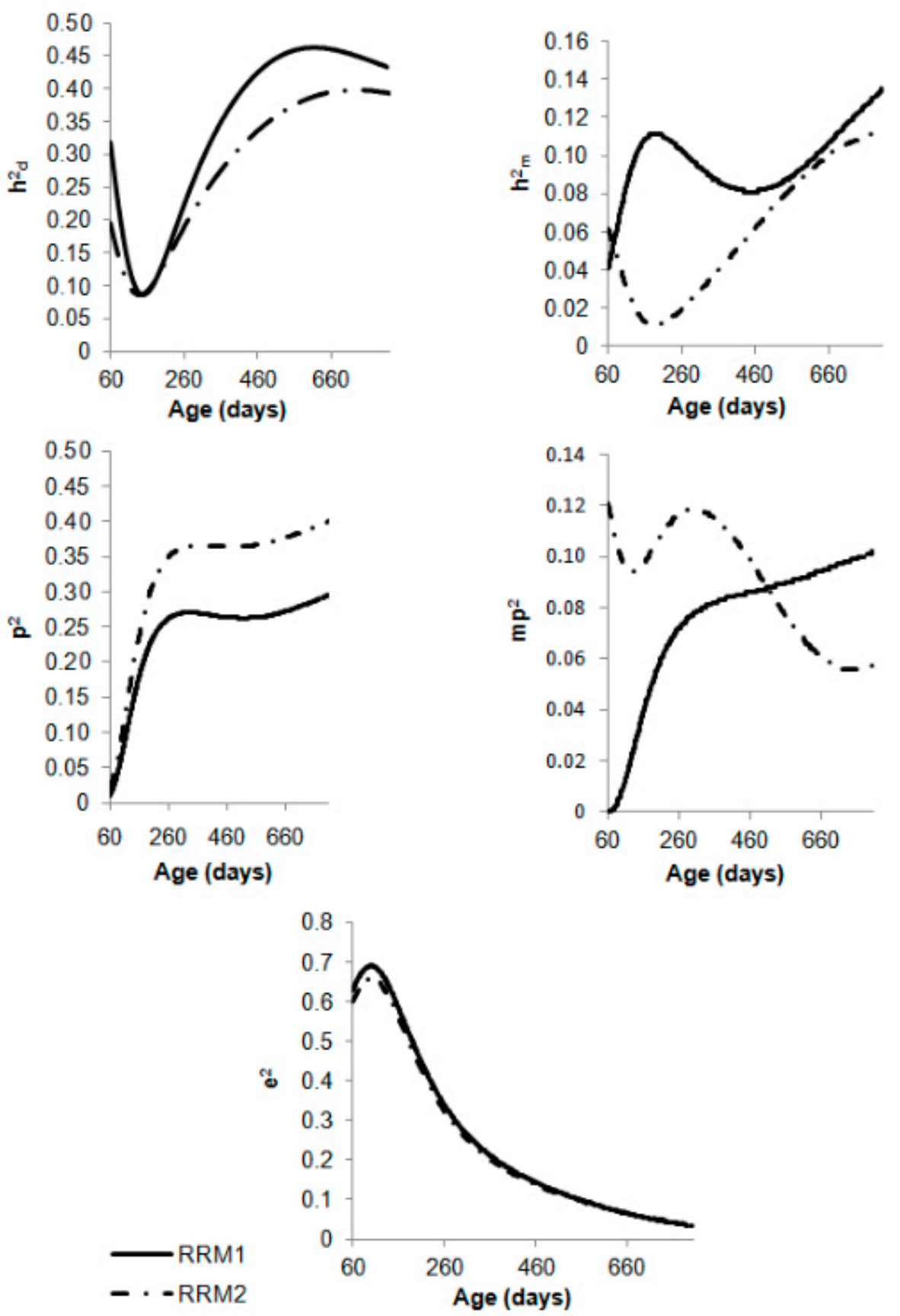

Figure 4. Direct $\left(h^{2} d\right)$ and maternal $\left(h^{2} m\right)$ heritabilities, and proportions of variances of direct permanent environmental $\left(\mathrm{p}^{2}\right)$, maternal permanent environmental $\left(\mathrm{mp}^{2}\right)$, residual $\left(\mathrm{e}^{2}\right)$ in relation to the total phenotypic variance obtained for the files RRM1 (full lines) and RRM2 (broken lines) to body weight. 
The behavior of the estimates of genetic maternal heritabilities $\left(\mathrm{h}_{\mathrm{m}}^{2}\right)$ was divergent in both models. While $\mathrm{h}_{\mathrm{m}}^{2}$ increased at the beginning in RRM1, it decreased until 240 days and increased after that in RRM2. Results in RRM2 were not biologically consistent. The estimates ranged from 0.04 to 0.14 in RRM1 and from 0.01 to 0.11 in RRM2. Values of the same magnitude were reported by Menezes (2010) and Sousa Júnior et al. (2010), who found $\mathrm{h}_{\mathrm{m}}^{2}$ around 0.10 in Tabapuã beef cattle. Furthermore, the behavior was divergent in the RRM1 model when it was observed as an oscillation during the trajectory, with an increase, decrease, and another increase. The decrease in RRM1 initiated at about 240 to around 450 days, where a new increase was observed. However, in RRM2, a decrease was observed from 60 days and a new ascendance at about 240 days. These results may indicate that the maternal influence remains even with mature age. This behavior is divergent from those reported by Baldi et al. (2010) and Menezes (2010), who reported a decline of $\mathrm{h}_{\mathrm{m}}{ }_{\mathrm{m}}$ from 400 and 240 days old, respectively.

For the direct permanent environmental component, as a proportion of phenotypic variance $\left(\mathrm{p}^{2}\right)$, RRM1 and RRM2 presented a similar behavior of the curve, which was a crescent from 60 to 240 days with a slight decrease around 300 days and a slight increase to the end of the growth curve (Figure 4). This behavior agrees with the results that were reported by Boligon et al. (2009) in Nellore beef cattle, who found estimates of direct permanent environmental variance as a proportion of phenotypic variance that ranged from 0.40 to 0.60 , increased up to 300 days, showed a slight reduction also around 300 days old, and slightly increased until the end of the trajectory.

Estimates of maternal permanent environmental component $\left(\mathrm{mp}^{2}\right)$, as a proportion of phenotypic variance for the file containing the animals from the ET technique (RRM2), were divergent from those that excluded them from analysis (RRM1). RRM1 had a continuous increase along the curve. However, RRM2 showed an oscillation from 60 to 260 days, the age at which an abrupt decline was initiated until the end of the trajectory (Figure 4). Bilhassi et al. (2010) also found contrasting behavior among estimates of $\mathrm{mp}^{2}$ that did or did not include animals from ET in Simmental beef cattle.

The behavior of $\mathrm{mp}^{2}$ in RRM2 indicates that the effect caused by maternal environment in the pre-weaning is attenuated over the life of the animal, probably due to other factors that influence it after this period. This result was similar to those reported by Baldi et al. (2010) and Boligon et al. (2009) in Canchim and Nellore cattle, respectively. Without biological explanation for the behavior of $\mathrm{mp}^{2}$ in RRM1, the data structure is probably the reason for this abrupt and continuous growth. In Tabapuã beef cattle, Menezes (2010) observed a sudden growth that was outside the biological reality at the end of the growth curve.

With the decline from 100 days old, estimates of the residual component as a proportion of phenotypic variance $\left(\mathrm{e}^{2}\right)$ were similar in RRM1 and RRM2 and slightly lower in RRM2 (Figure 4). The lower magnitude values in RRM2 may indicate a potential gain in accuracy if these animals were included in the analysis. Therefore, from this similarity in behavior, it can be inferred that the use of ET animals, with appropriate use of the methodologies, is feasible in the genetic evaluation of Simmental cattle.

Estimates of direct genetic correlations for RRM1 and RRM2 models are illustrated in Figure 5. As we can observe, these correlations were, in general, from moderate to high in magnitude and positive and higher at closer ages, confirming the results commonly reported in the literature (Nephawe, 2004; Boligon et al., 2009; Baldi et al., 2010; Menezes, 2010). These results suggest that selection for weights at earlier ages will change the weight at later ages. 

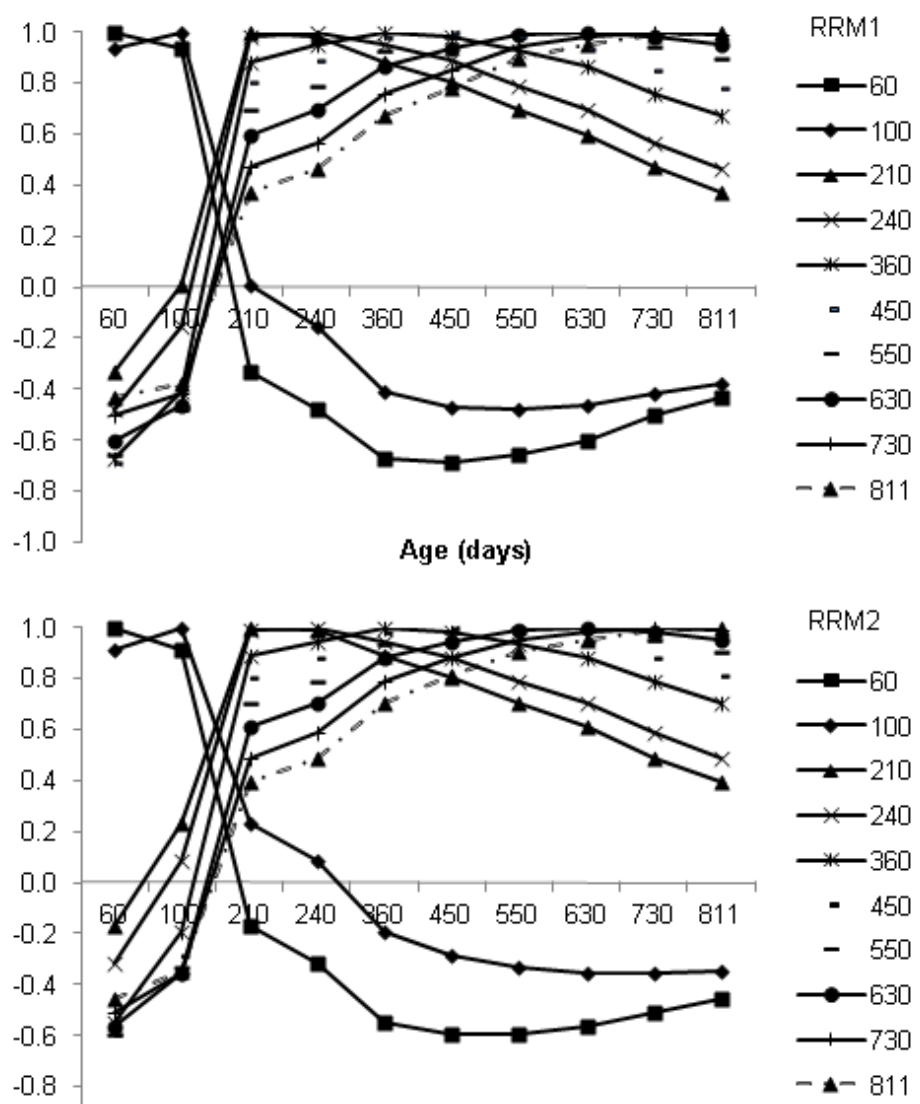

Age (days)

Figure 5. Estimates of additive genetic direct correlations for body weight at different ages for the models RRM1 and RRM2.

In these results, an exception must be made at ages P60 and P100, for all (co)variance components because negative correlations were observed among these and the other ages analyzed. Problems with the polynomial function to estimate the (co)variance components and genetic parameters at the extremities of the trajectory may have caused these correlations, which in theory are not expected, because there is structural dependence on the trait, which is the sum of the gain weight throughout the life of the animal.

The direct permanent environmental correlations were similar in RRM1 and RRM2 and also distanced themselves from the unit; as the ages distanced, the correlations were smaller and even became negative at the extremities of the growth curve (Figure 6). Baldi et al. (2010) reported direct permanent environmental correlations that were higher in closer ages and generally of the same magnitude to the correlations found in this study. Arango et al. (2004) estimated direct permanent environmental correlations in intermediate ages with oscillatory values, but they were generally close to 0.60 , and there were even lower correlations among extreme ages. 


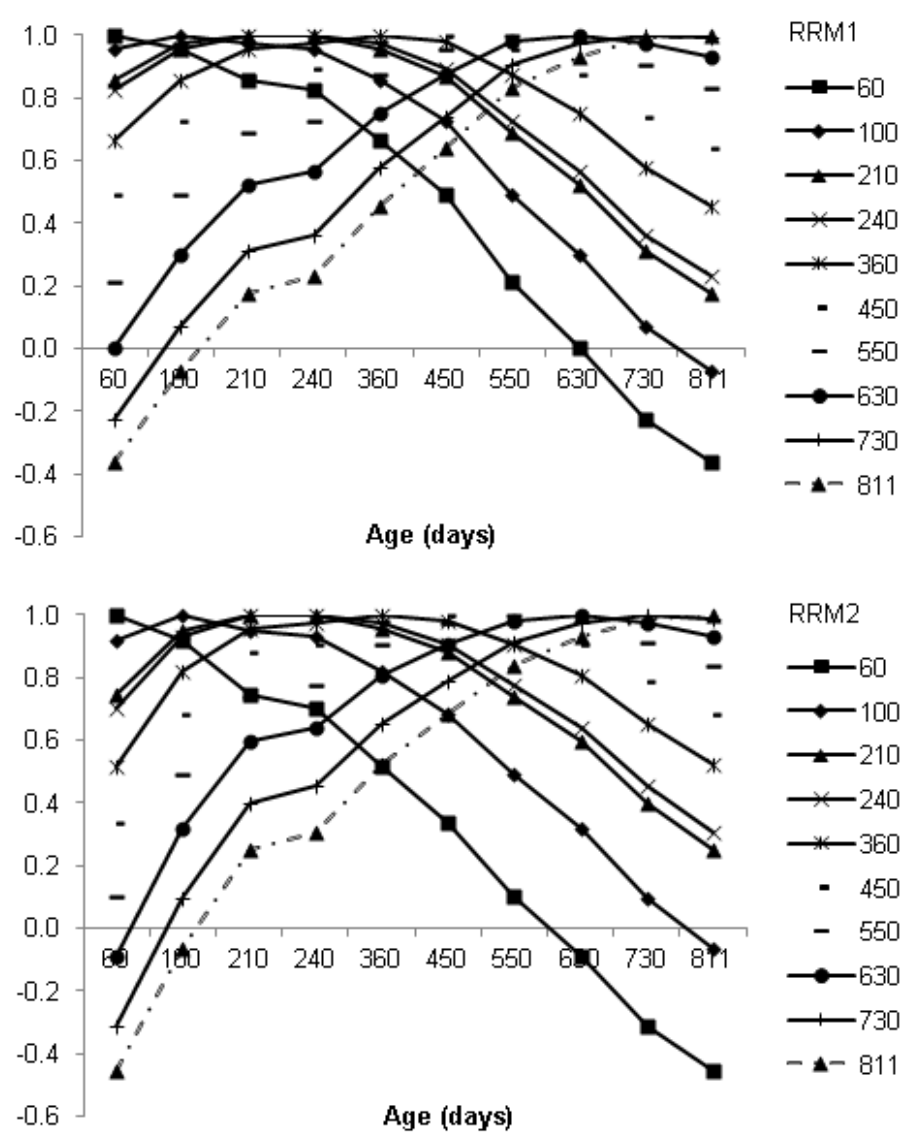

Figure 6. Estimates of direct permanent environmental correlations for body weight at different ages for the models RRM1 and RRM2.

High values of direct permanent environmental correlations were obtained for weights at 100 and 240 days old (up to 0.83 for RRM1 and 0.70 for RRM2) and of 450 days old until the end of the trajectory studied, with values higher than 0.64 in RRM1 and 0.68 in RRM2. These results are of a higher magnitude that those observed by Boligon et al. (2009), who found values varying from 0.60 to 0.79 among the ages of birth at 540 days old and 0.56 to 0.84 at 730 days until the end of the period studied.

As can be observed in (Figure 7), the estimates of maternal additive genetic correlations were generally similar, and they distanced themselves as the ages also distanced, generating high and positive estimates especially in adjacent ages and also negative estimates among the most distanced ages of the growth trajectory of the animals.

High values that were found among the ages 100,240, and 360 days may indicate that the same genes control maternal effects for weight until these ages (Boligon et al., 2010) and corroborate previously reported results in Tabapuã cattle (Dias et al., 2006; Sousa Júnior et al., 2010; Menezes (2010), Nellore cattle (Nobre et al., 2003; Boligon et al., 2009), and Canchim 
cattle (Baldi et al., 2010). However, negative values reported for the most distant ages in this study differ from those of other studies in the literature (Nobre et al., 2003; Baldi et al., 2010; Menezes, 2010). The difficulty of the polynomial function to estimate genetic parameters in the extremities of the trajectory may have caused such correlations to be incompatible with biological aspects of beef cattle.

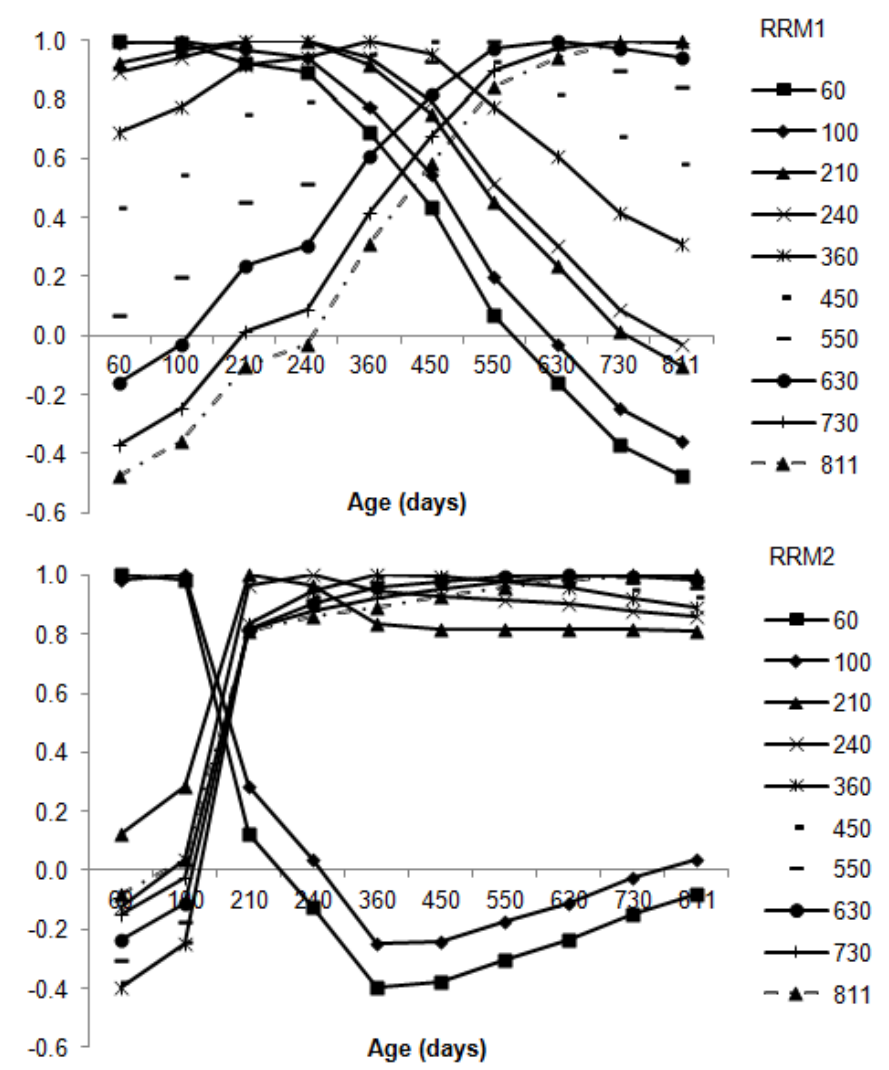

Figure 7. Estimates of maternal additive genetic correlations for body weight at different ages for the models RRM1 and RRM2.

Except for the weights at 60 and 100 days, where negative correlations were observed in RRM2, both models (RRM1 and RRM2) produced maternal permanent environmental correlations of similar magnitudes for the ages tested, presenting lower values at more distant ages and being higher mainly among the ages until weaning (Figure 8). These results agree with those reported by Menezes (2010), who also found correlations of lower magnitude as the ages distanced themselves, and contrast with those reported by Dias et al. (2006) and Baldi et al. (2010), who found estimates, in general, that were close to the unit in Tabapuã and Canchim beef cattle, respectively. Values from mean to the high magnitude that was observed until weaning may suggest the importance of females with excellent maternal ability by indicating that the effects generated by the environment provided by the dam during pre-weaning is important throughout the life of the animal (Menezes, 2010). 

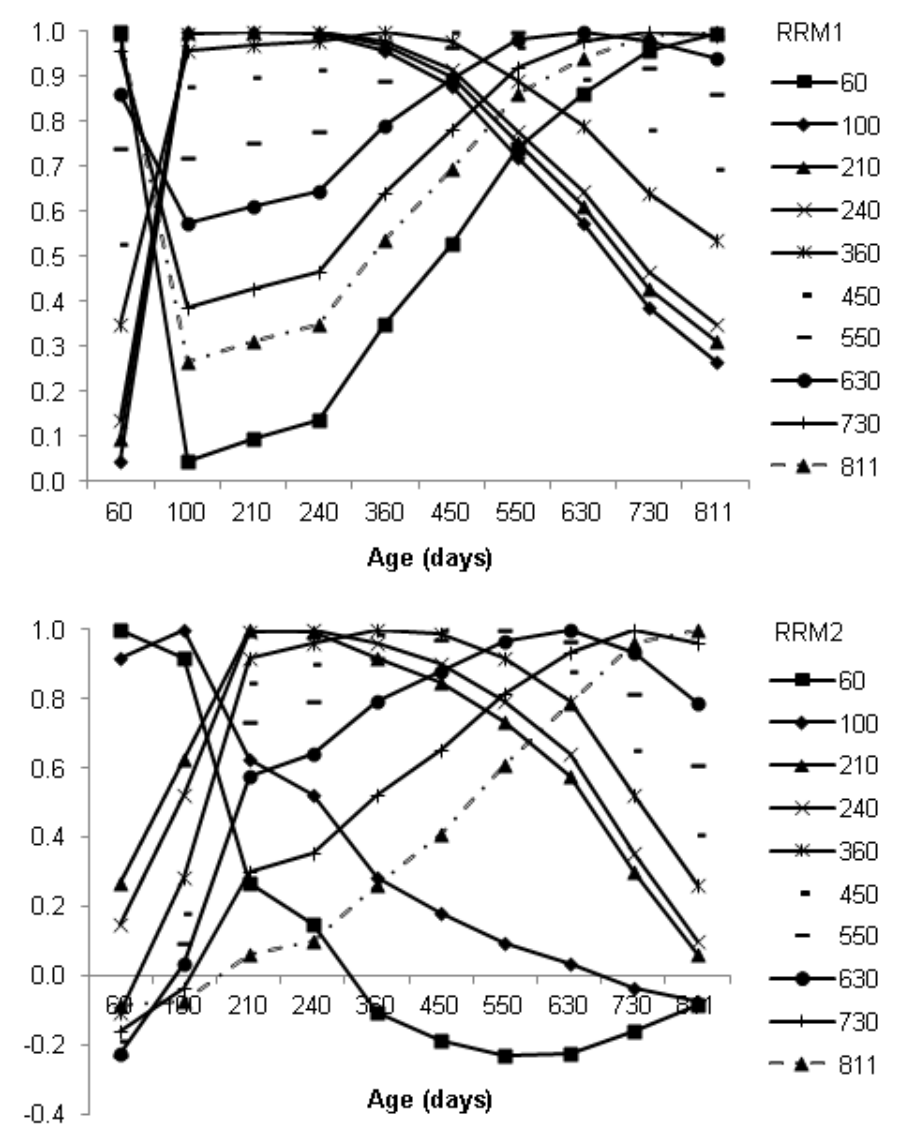

Figure 8. Estimates of maternal permanent environmental correlations for body weight at different ages for the models RRM1 and RRM2.

As can be observed in (Figure 9), the phenotypic correlations for both models were similar and decreased as the ages distanced themselves, generating negative correlations for the ages of 60 and 100 days and the other ages, perhaps because of problems with the polynomial function. Marques et al. (2000) worked with animals of the Simmental breed in two-trait analyses and found values of higher magnitude in closer ages, noting values of 0.74 at 205 and 100 days and 0.64 at 205 and 550 days.

\section{CONCLUSIONS}

The inclusion of animals from the ET technique in the process of genetic evaluation can be made using random regression models. The inclusion of these animals could provide a potential gain in accuracy and higher genetic gain per unit of time because of the reduced generation interval that can be obtained by using this reproduction technique. 

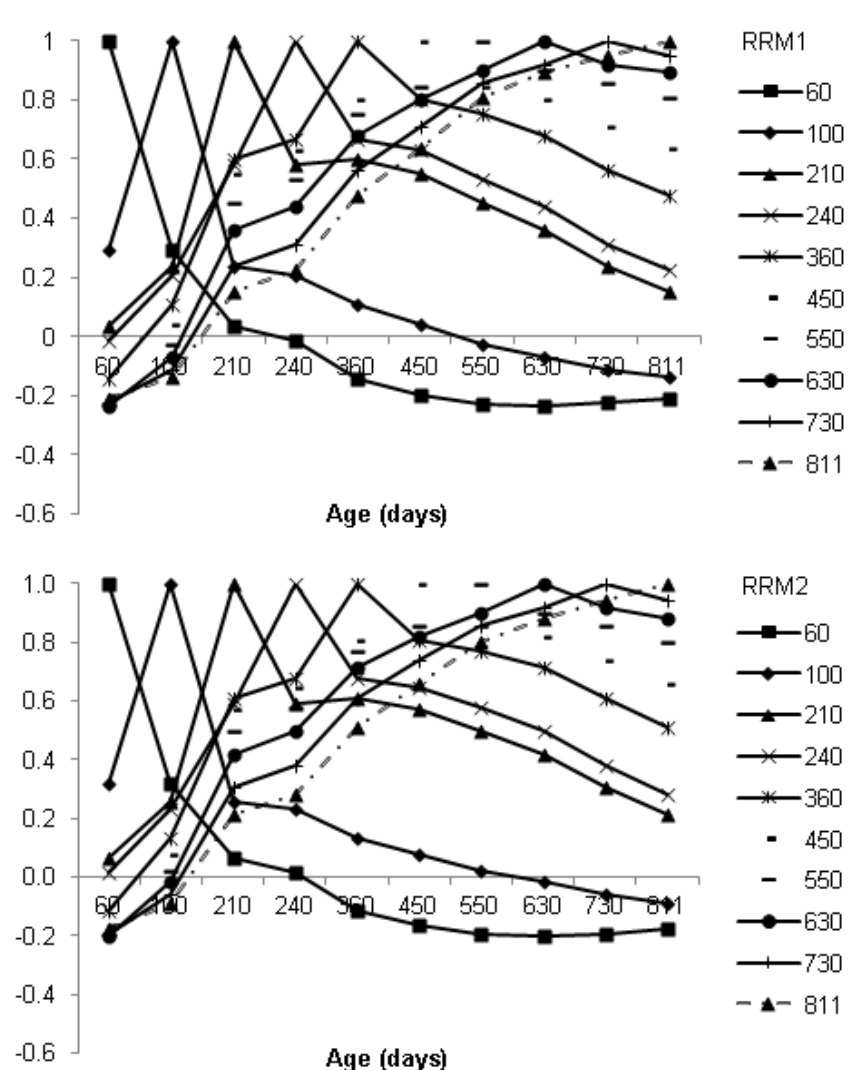

Figure 9. Estimates of phenotypic correlations for body weight at different ages for the models RRM1 and RRM2.

\section{ACKNOWLEDGMENTS}

The authors thank Associação Brasileira de Criadores das Raças Simental e Simbrasil (Brazilian Association of Simbrasil and Simmental Cattle Breeders, ABCRSS) for providing the data that were used in this study.

\section{REFERENCES}

Albuquerque LG and Meyer K (2001). Estimates of covariance functions for growth from birth to 630 days of age in Nelore cattle. J. Anim. Sci. 79: 2776-2789.

Andrade JC, Oliveira MA, Lima PF, Santos Filho AS, et al. (2002). Use of steroid hormone treatments prior to superovulation in Nelore donors. Anim. Reprod. Sci. 69: 9-14.

Arango JA, Cundiff LV and Van Vleck LD (2004). Covariance functions and random regression models for cow weight in beef cattle. J. Anim. Sci. 82: 54-67.

Baldi F, Albuquerque LG and Alencar MM (2010). Random regression models on Legendre polynomials to estimate genetic parameters for weights from birth to adult age in Canchim cattle. J. Anim. Breed. Genet. 127: 289-299.

Bilhassi TB, Neto FRA, Diaz IDP, Pessoa MC, et al. (2010). Efeito da Inclusão de Animais Provindos de Transferência de Embriões na Avaliação Genética de Medidas Ponderais na Raça Simental. Proceedings of the 8th Simpósio da Sociedade Brasileira de Melhoramento Animal, Maringá. 
Boligon AA, Mercadante MEZ, Baldi Rey FS, Lobo RB, et al. (2009). Multi-trait and random regression mature weight heritability and breeding value estimates in Nelore cattle. S. Afr. J. Anim. Sci. 39: 145-148.

Boligon AA, Mercadante ME, Forni S, Lobo RB, et al. (2010). Covariance functions for body weight from birth to maturity in Nellore cows. J. Anim. Sci. 88: 849-859.

De Bem AR, Rumpf R and Sousa RV (1993). Manual Sobre Transferência e Micromanipulação de Embriões nas Espécies Bovina e Eqüina. Embrapa - Cenargen, Brasília.

Demczuk E, Kozicki LE, Pontelli ES and Salles JO (1998). Transferência de embrião em vacas da raça Simental na região noroeste do Paraná e Sul do Mato Grosso do Sul. Braz. J. Vet. Res. Anim. Sci. 35: 174-177.

Dias LT, Albuquerque LG, Tonhati H and Teixeira RA (2006). Estimação de parâmetros genéticos para peso do nascimento aos 550 dias de idade para animais da raça Tabapuã utilizando-se modelos de regressão aleatória. $R$. Bras. Zootec. 35: 1915-1925.

Dobrinsky JR (2001). Embryo preservation and transfer technology for swine production. J. Anim. Sci. 79: 31.

Krejcová H, Mielenz N, Pribyl J and Schuler L (2007). Estimation of genetic parameters for daily gains of bulls with multitrait and random regression models. Arch. Tierzucht 50: 37-46.

Marques LFA, Pereira JCC, Oliveira HN, Silva MA, et al. (2000). Análise de característica de crescimento da raça Simental. Arq. Bras. Med. Vet. Zootec. 52: 527-533.

Menezes G (2010). Uso de Polinômios Segmentados na Modelagem de Dados Longitudinais de Ponderal em Bovinos da Raça Tabapuã. Doctoral thesis, Universidade Federal de Viçosa, UFV, Viçosa.

Meyer K (1998). Estimating covariance functions for longitudinal data using random regression model. Genet. Sel. Evol. 30: $221-240$.

Meyer K (2000). Random regression to model phenotypic variation in monthly weights of Australian beef cows. Livest. Prod. Sci. 65: 19-38.

Meyer K (2004). Scope for a random regression model in genetic evaluation of beef cattle for growth. Livest. Prod. Sci. 86: 69-83.

Meyer K (2007). WOMBAT: a tool for mixed model analyses in quantitative genetics by restricted maximum likelihood (REML). J. Zhejiang Univ. Sci. B 8: 815-821.

Nephawe KA (2004). Application of random regression models to the genetic evaluation of cow weight in Bonsmara cattle of South Africa. S. Afr. J. Anim. Sci. 34: 166-173.

Nobre PR, Misztal I, Tsuruta S, Bertrand JK, et al. (2003). Analyses of growth curves of nellore cattle by multiple-trait and random regression models. J. Anim. Sci. 81: 918-926.

Patterson HD and Thompson R (1971). Recovery of inter-block information when block sizes are unequal. Biometrika 58: 545-554.

SAS (2004). Statistical Analysis Software. SAS Institute Inc., Cary.

Sousa Júnior SCS, Oliveira SMP, Albuquerque LG, Boligon AA, et al. (2010). Estimação de funções de covariância para características de crescimento da raça Tabapuã utilizando modelos de regressão aleatória. R. Bras. Zootec. 39: 1037-1045.

Van Vleck LD (1990). Alternative animal models with maternal effects and foster dams. J. Anim. Sci. 68: 4026-4038.

Genetics and Molecular Research 12 (4): 5889-5904 (2013) 